\title{
Investigation of SBRT and IMRT Techniques in Lung Radiotherapy: A Dosimetric Study
}

\author{
Akciğer Radyoterapisinde SBRT ve IMRT Tekniklerinin İncelenmesi: Dozimetrik Çalışma
}

Elif Ates

İstanbul Aydın Üniversitesi, Sağlık Bilimleri Enstitüsü, Sağlık Fiziği Programı, İstanbul, Türkiye.

\begin{abstract}
Objective: In our study, we aimed to compare the dose distrubutions of Accuray brand TomoTherapy device Volo treatment planning system lung stereoactic body radiation therapy (SBRT) and intensity-adjusted radiation therapy in cancer dose distributions obtained using (IMRT) techniques and environmental doses.

Matetial and Method: Computed Tomography (CT) images of 7 patients were transferred to the MIM contouring station for dose measurement. CT target volume via image; PTV right or left lung, critical organs: heart, costa, esophagus, medulla, bilateral lung transferred to planning system. Lung tumors created virtually.In study $1 \mathrm{~cm}$ tumor of the size it is formed to be $\mathrm{cm}, 3 \mathrm{~cm}$ and $5 \mathrm{~cm}$. Spouse as lungtumor sizes change.in time, the cross-section (jaw) area of the TomoTherapy device will also be $1 \mathrm{~cm}, 2.5 \mathrm{~cm}$ and $5 \mathrm{~cm}$ it has been modified and tested for SBRT and IMRT techniques at each tumor size.

Results: PTV dose treatment plans have been established to be $60 \mathrm{~Gy}$ and 3 fractions. The study $1 \mathrm{~cm}$ tumor of the size SBRT and IMRT techniques compared to the treatment of lung cancer as a result for $1 \mathrm{~cm}$ jaw, $2.5 \mathrm{~cm}$ jaw and $5 \mathrm{~cm}$ jaw in cm tumor size and $5 \mathrm{~cm}$ tumor PTV max, D95 values for $1 \mathrm{~cm}$ jaw used in size and bilateral, which is the critical organs. A significant difference in lung max values was found in favor of $S B R T(p<0.05)$. 3 $\mathrm{cm}$ tumor size used in $1 \mathrm{~cm}, 2.5 \mathrm{~cm}$ and $5 \mathrm{~cm}$ jaw areas and $5 \mathrm{~cm}$ treatment compared to 2.5 and $5 \mathrm{~cm}$ jaw areas used in cm tumor bouts statistics on ptv max and bilateral lung max values at the end of the analysis, an agreed difference was found in favor of the SBRT $(p<0.05)$ during treatment periods. At the end of statistical analysis in $1 \mathrm{~cm}$ jaw area used in $1 \mathrm{~cm}$ tumor size a significant difference in favor of IMRT has been identified. $(p<0.05)$ and no significant differences were found for other critical organs $(p>0.05)$.

Conclusion: As a result, $1 \mathrm{~cm}, 3 \mathrm{~cm}$ and $5 \mathrm{~cm}$ tumor sizes used in $1 \mathrm{~cm}, 2.5 \mathrm{~cm}$ and $5 \mathrm{~cm}$ section (jaw) areas according to both techniques preserved critical organs. But the SBRT technique showed better results in terms of target volume (PTV) and both lungs.
\end{abstract}

$\ddot{O} Z E T$

Amaç: Çalışmamızda Accuray marka Tomoterapi cihazının volo tedavi planlama sistemiyle akciğer kanserinde Stereotaktik Beden Radyoterapisi (SBRT) ve Yoğunluk Ayarlı Radyoterapi (IMRT) teknikleri kullanilarak elde edilen doz dağılımlarının ve çevre dozların karşılaş̧ırılması amaçlanmıştır.

Gereç ve Yöntem: Doz ölçümü için 7 hastanın Bilgisayarlı Tomografi (BT) görüntüleri üç boyutlu konturlama yazlım sistemi (MIM) konturluma istasyonuna aktarılmıştır. Tedavi başlamadan önce çekilmiş bilgisayarlı tomografi görüntüleri, network sistemi yardımılla üç boyutlu konturlama sistemine aktarllarak, hastanın tümör ve kritik organları belirlenmiştir. BT görüntüsü üzerinden hedef hacim; planlanan hedef hacim (PTV) sağ veya sol akciğer, kritik organlar; kalp, kosta, özefagus, medulla, bilateral akciğer (her iki akciğer) belirlenerek Tomotheraphy Volo Planlama Sistemi'ne aktarılmıştır. Çalışmada sanal olarak oluşturulan akciğer tümörleri 1 $\mathrm{cm}, 3 \mathrm{~cm}$ ve $5 \mathrm{~cm}$ olacak şekilde oluşturulmuştur. Akciğer tümör boyutları değişirken eş zamanlı olarak tomoterapi cihazının kesit (jaw) alanı da $1 \mathrm{~cm}, 2.5 \mathrm{~cm}$ ve $5 \mathrm{~cm}$ olacak şekilde değiştirilerek her bir tümör boyutunda SBRT ve IMRT teknikleri için denenmiştir. PTV dozu 60 Gy ve 3 fraksiyon olacak şekilde tedavi planlar oluşturulmuştur. Bulgular: Yapılan çalışma sonucunda Akciğer kanserinin tedavisinde karşılaştırılan SBRT ve IMRT tekniklerinden $1 \mathrm{~cm}$ 'lik tümör boyutunda $1 \mathrm{~cm}$ 'lik jaw, $2.5 \mathrm{~cm}$ 'lik jaw ve $5 \mathrm{~cm}$ 'lik jaw için ve $5 \mathrm{~cm}$ 'lik tümör boyutunda kullanılan $1 \mathrm{~cm}$ 'lik jaw için PTV max, D95 değerleri ve kritik organ olan bilateral akciğer max değerleri üzerinde SBRT lehine anlamlı bir farklılık saptanmıştır $(p<0.05) .3 \mathrm{~cm}$ 'lik tümör boyutunda kullanılan $1 \mathrm{~cm}$ 'lik, $2.5 \mathrm{~cm}$ 'lik ve $5 \mathrm{~cm}$ 'lik jaw alanlarında ve $5 \mathrm{~cm}$ 'lik tümör boutunda kullanılan 2,5 ve $5 \mathrm{~cm}$ 'lik jaw alanlarında karşılaştırılan tedavi yöntemleri için PTV max ve bilateral akciğer max değerleri üzerinde yapılan istatistiksel analiz sonucunda SBRT lehine anlamlı bir farklılık saptanmıştır.( $p<0,05)$ Tedavi sürelerinde ise 1 cm 'lik tümör boyutunda kullanılan $1 \mathrm{~cm}$ 'lik jaw alanında istatistiksel analiz sonucunda IMRT lehine anlamlı bir farklılık saptanmıştır $(p<0,05)$ ve diğer kritik organlar için ise anlamlı bir farklılık saptanmamıştır $(p>0,05)$.

Sonuç: Sonuç olarak, $1 \mathrm{~cm}, 3 \mathrm{~cm}$ ve $5 \mathrm{~cm}$ 'lik tümör boyutlarında kullanılan $1 \mathrm{~cm}, 2.5 \mathrm{~cm}$ ve $5 \mathrm{~cm}$ kesit (jaw) alanlarına göre her iki teknikte kritik organlar korumuştur. Fakat SBRT tekniğinin hedef hacim (PTV) ve her iki akciğer açısından daha iyi sonuçlar verdiği görülmüştür.
Keywords:

Lung Cancer

Intensity Modulated Radiotherapy

Stereotactic Body Radiotherapy

Radiotherapy Planning

Dosimetry

\section{Anahtar Kelimeler:}

Akciğer Kanseri

Yoğunluk Ayarlı Radyoterapi

Stereotaktik Beden Radyoterapisi

Radyoterapi Planlama,

Dozimetri

Correspondence: Elif ATEŞ. İstanbul Aydın Üniversitesi, Sağlık Bilimleri Enstitüsü, Sağlık Fiziği Programı, İstanbul, Türkiye. E-posta: elifates@stu.aydin.edu.tr

Cite as: Ates E. Investigation of SBRT and IMRT Techniques in Lung Radiotherapy: A Dosimetric Study. Phnx Med J.

2021;3(3):113-117.

Received: 03.07 .2021

Accepted: 15.07 .2021 


\section{GíRIS}

Akciğer kanseri, kansere bağlı ölümlerin en önemli nedenidir ve her yıl 1 milyonun üzerinde insan bu nedenle ölmektedir (1). Günümüzde akciğer kanserinin tedavisinde radyoterapi (RT) çok önemli bir yer tutar. Radyoterapi, iyonlaştırıcı radyasyon kullanarak kanser hastalığının tedavi edilmesidir (2). Radyoterapinin amacı, tümörlü dokunun yok edilmesi ve aynı zamanda sağlıklı dokuların korunmasıdır. Gelişen teknoloji ile birlikte birçok etkili RT yöntemleri kullanılmaktadır. SBRT (stereotaktik beden radyoterapisi) ve IMRT (yoğunluk ayarlı radyoterapi) bu etkili yöntemlerden birisidir (3). SBRT tekniği çok yüksek dozlardaki radyasyonun yüksek hassasiyetle farklı açılardan hedef organa gönderildiği tedavi yöntemidir (4). Gönderilen radyasyonun hedefte en yüksek dozu alması amaçlanırken çevre dokuların en az dozu alması sağlanmaktadır $(5,6)$. SBRT tek doz şeklinde yada birkaç doz olarak uygulanabilmektedir. IMRT ise yoğunluk farklılıkları oluşturulmuş alanlardan tedavi yapılan bir yöntemdir. Her iki yöntemde de çevredeki sağlam dokular korunarak etkili bir tedavi uygulaması amaçlanmaktadır $(7,8)$.

$\mathrm{Bu}$ çalışmada; her plan için Tomoterapi cihazında tümör boyutu ve cihazın kesit (jaw) alanı parametreleri değiştirilip tedavi planları oluşturulmuştur. Tedavi planları oluşturulup doz-hacim histogramları elde edilerek karşılaştırılmıştır. İstatistiksel analiz sonucunda, akciğer kanserli hastalar için en uygun ve doğru tedavi tekniğini bulmak amaçlanmıştır.

\section{GEREÇ VE YÖNTEM}

Çalışma hastanenin TPS (Tedavi Planlama Sistemi) arşivinden (Accuray-Tomoterapi, Volo tedavi planlama sistemi) retrospektif olarak bulunan, RT uygulanmış akciğer kanserli hastalardan oluşan 7 kişilik hasta grubu seçilmiştir. $\mathrm{Bu}$ çalışma İstanbul Aydın Üniversitesi Girişimsel Olmayan Etik Kurulu'nun 23.12.2020 tarihinde yapılan olağan toplantısında alınan 2020/317 no'lu kararla onaylanmıştır. $\mathrm{Bu}$ hastalara ait planlama için çekilen bilgisayarlı tomografi (BT) verileri ile hastaların iki farklı yöntemdeki sanal tedavi planlamalarına ait parametreler kullanılmıştır. Aynı zamanda her hastanın tümör boyutları $1 \mathrm{~cm}, 3 \mathrm{~cm}$ ve $5 \mathrm{~cm}$ olacak şekilde yeniden çizilerek her iki tedavi tekniğinde de tümör boyutlarına göre planlamalar yapılmıştır.

- BT Simülatör: "Philips Brilliance" marka, "64 channel" model tüm vücut X-1şını BT cihazı kullanılmıştır.1-10 mm arasında olan kesit kalınlıkları değişik değerlerde seçilebilmektedir. Tedavi planlaması için öncelikle hastanın, BT cihazı ile üç boyutlu görüntüleri alınmıştır.

- $\quad$ RT Network Sistemi: Radyoterapi network sistemi, tedavide kullanılan tedavi cihazlarını, görüntüleme sistemlerini birbirine bağlayan ve bütün tedavi planlama sistemlerini aynı veri alanını kullanarak hızlı ve güvenilir bir şekilde bilgi aktarma,toplama ve depolama olanağ sağlar.

- MíM Konturlama Sistemi: "MİM" marka, "6.4.9" model konturlama sistemi kullanılmıştır. Konturlama sisteminin amacı, hastanın tedaviye başlamadan önce çekilmiş BT görüntüleri, network sistemi aracılı̆̆ 1 ile üç boyutlu konturlama sistemine aktarılarak hastanın hedef hacimi ve kritik organları belirlenir.

\section{- Tomoterapi Hi-Art Lineer Hizlandırıcı:}

Tomoterapi (Tomotherapy ${ }^{\circledR} \mathrm{H}^{\mathrm{TM}}$ ) cihaz1; $6 \mathrm{MV}$ tek foton enerjisine sahip, IMRT ve SBRT tekniğini uygulayabilen lineer hızlandırıcıdır. Bu cihaz BT cihazına benzemektedir. Hasta tedavi masasına yatırıldıktan sonra masa, cihazın geniş halka yapısının içine doğru hareket etmektedir.

- Tomoterapi Hi-Art Lineer Hızlandırıcı Tedavi Planlama Sistemi: "Volo (Accuray ${ }^{\circledR}$ Planing StationTomotherapy® $\mathrm{H}^{\mathrm{TM}}$ 2.1.1 version)" tedavi planlama sistemi kullanılmıştır. Tomoterapi Hi-Art tedavi planlama sistemi (TPS), Convolotion/Superposition algoritması ile ters planlama özelliğine sahip olup, sistemde sadece 6 MV'ye ait doz verisi bulunmaktadır.

- Uluslararası Radyasyon Ölçümleri ve Birimleri Komitesinin 50 ve 62 Numaralı Raporu: Radyoterapide üç boyutlu tedavi planlaması için gerekli olan hedef hacimlerin (GTV, CTV, PTV) ve kritik organ (OAR)'ların ayrıntılı olarak tanımlayan rapor referans olarak alınmıştır $(9,10,11)$. Çalışmada sanal olarak oluşturulan $1 \mathrm{~cm}, 3 \mathrm{~cm}$ ve $5 \mathrm{~cm}$ tümör boyutlarına sahip akciğer kanserli hastalar için RT planlanan ve tomoterapi cihazında SBRT ve IMRT tedavi teknikleri ile hazırlanan planlar, PTV ve risk altındaki organların aldığı dozlar doz-hacim histogramları kullanılarak doz karşılaştırılması yapılmıştır. Retrospektif olarak planlanan bu çalışmada, hastaların $3 \mathrm{~mm}$ kesit kalınlığındaki BT verileri, MIM konturlama sistemine aktarılarak, her hasta için akciğer hedef hacmi ve kritik organlar, radyasyon onkoloğu tarafından konturlanmıştır. Her hasta için SBRT ve IMRT tekniklerine göre tedavi planları yapılarak doz-volüm histogramları (DVH) incelenmiştir. DVH'lerden, PTV için D\%95 ve Dmean doz değerleri kaydedilmiştir. Kritik, kalp, kosta, özefagus, medulla ve bilateral akciğerlerin dozvolüm parametrelerinden V5, Dmax ve Dmean değerleri belirlenerek, karşılaştırılması yapılmıştır.

İstatistiksel Analiz: Araştırmamızda iki bağımsız gruba sahip belirli bir nicel değişkenin ortalamalarını karşılaştırmak amacıyla ve verilerimizin normal dağılıma uygun olmadığı durumda iki bağımsız grubun ortalamalarını karşılaştırmak için Mann-Whitney U testi kullanılmıştır. İstatistiksel anlamlılık için p değerinin 0.05 ' ten küçük olması gerekliliği kabul edilmiştir.

\section{BULGULAR}

Çalışmada 7 hasta için hem SBRT ve hem IMRT tedavi planlarından elde edilen doz dağılımları, tümör boyutlarının sirasiyla $1 \mathrm{~cm}, 3 \mathrm{~cm}$ ve $5 \mathrm{~cm}$; ve tomoterapi cihaz kesit alanının sirasıyla $1 \mathrm{~cm}, 2.5 \mathrm{~cm}, 5 \mathrm{~cm}$ olarak seçilmesiyle planlanan hedef hacim ve kritik organlar için minimum, maksimum, ortalama dozlar ve dozhacim parametreleri, ortalama \pm standart sapma olarak belirlenmiştir.

$1 \mathrm{~cm}$ 'lik tümör ve $1 \mathrm{~cm}$ lik kesit alanı için Mann Whitney U testi sonucunda PTV MAX ve PTV D95'euygulanan SBRT ve IMRT teknikleri arasında SBRT lehine anlamlı farklılık saptanmıştır ( $\mathrm{p}<0.05)$. $1 \mathrm{~cm}$ 'lik tümör ve $1 \mathrm{~cm}$ lik kesit alanında her iki akciğer max için uygulanan SBRT ve IMRT teknikleri arasında SBRT lehine anlamlı farklılık saptanmıştır $(\mathrm{p}<0.05) .1 \mathrm{~cm}$ 'lik tümör ve $1 \mathrm{~cm}$ lik kesit alanında SBRT ve IMRT süreleri arasında IMRT lehine anlamlı fark tespit edilmiştir $(\mathrm{p}<0.05)$ (Tablo 1). 


\section{Phnx Med J. November 2021, Volume 3 No 3}

Tablo 1: PTV max, PTV D95, her iki akciğer max, ortalama ve sürenin $1 \mathrm{~cm}$ 'lik tümör boyutunda $1 \mathrm{~cm}$ jaw kullanılarak elde edilen doz değerlerinin ortalama, standart sapmaları, minimum, maksimum ve p değerleri.

\begin{tabular}{|c|c|c|c|c|c|c|c|c|c|}
\hline & & MeanRank & Sum of Ranks & $\mathbf{X}$ & SS & Min & $\operatorname{Max}$ & M-U & $\mathbf{p}$ \\
\hline \multirow{2}{*}{ PTV max } & SBRT & 11.00 & 77.00 & \multirow{2}{*}{70.7} & \multirow{2}{*}{7.31} & \multirow{2}{*}{62.99} & \multirow{2}{*}{79.12} & \multirow{2}{*}{0.00} & \multirow{2}{*}{$0.02 *$} \\
\hline & IMRT & 4.00 & 28.00 & & & & & & \\
\hline \multirow{2}{*}{ PTV D95 } & SBRT & 10.14 & 71.00 & \multirow{2}{*}{61.5} & \multirow{2}{*}{2.51} & \multirow{2}{*}{58.00} & \multirow{2}{*}{65.39} & \multirow{2}{*}{60.00} & \multirow{2}{*}{$0.02 *$} \\
\hline & IMRT & 4.86 & 34.00 & & & & & & \\
\hline \multirow{2}{*}{ Her İki Akciğer Max } & SBRT & 11.00 & 77.00 & \multirow{2}{*}{70.72} & \multirow[b]{2}{*}{7.31} & \multirow[b]{2}{*}{62.99} & \multirow[b]{2}{*}{79.12} & \multirow[b]{2}{*}{0.00} & \multirow[b]{2}{*}{$0.00 *$} \\
\hline & IMRT & 4.00 & 28.00 & & & & & & \\
\hline \multirow{2}{*}{ Her İki Akciğer Ortalama } & SBRT & 7.57 & 53.00 & \multirow{2}{*}{1.45} & \multirow{2}{*}{0.39} & \multirow{2}{*}{0.85} & \multirow{2}{*}{1.97} & \multirow{2}{*}{24.00} & \multirow{2}{*}{0.95} \\
\hline & IMRT & 7.43 & 52.00 & & & & & & \\
\hline \multirow{2}{*}{ Süre } & SBRT & 5.29 & 37.00 & \multirow{2}{*}{1188} & \multirow{2}{*}{259.3} & \multirow{2}{*}{796.9} & \multirow{2}{*}{1801.4} & \multirow{2}{*}{9.00} & \multirow{2}{*}{$0.048 *$} \\
\hline & IMRT & 9.71 & 68.00 & & & & & & \\
\hline
\end{tabular}

Hacim.

Tablo 2: PTV max, PTV D95, her iki akciğer max, ortalama ve sürenin $3 \mathrm{~cm}$ 'lik tümör boyutunda $2.5 \mathrm{~cm}$ jaw kullanılarak elde edilen doz değerlerinin ortalama, standart sapmaları,minimum, maksimum ve p değerleri.

\begin{tabular}{|c|c|c|c|c|c|c|c|c|c|}
\hline & & $\begin{array}{c}\text { Mean- } \\
\text { Rank }\end{array}$ & $\begin{array}{l}\text { Sum of } \\
\text { Ranks }\end{array}$ & $\mathbf{X}$ & SS & Min & Max & M-U & $\mathbf{p}$ \\
\hline \multirow[t]{2}{*}{ PTV max } & SBRT & 11.00 & 77.00 & \multirow{2}{*}{70.53} & \multirow{2}{*}{7.13} & \multirow{2}{*}{61.45} & \multirow{2}{*}{78.62} & \multirow{2}{*}{0.00} & \multirow{2}{*}{$0.002^{*}$} \\
\hline & IMRT & 4.00 & 28.00 & & & & & & \\
\hline PTV & SBRT & 8.43 & 59.00 & \multirow{2}{*}{60.14} & \multirow{2}{*}{1.05} & \multirow{2}{*}{58.96} & \multirow{2}{*}{62.44} & \multirow{2}{*}{18.00} & \multirow{2}{*}{0.41} \\
\hline D95 & IMRT & 6.57 & 46.00 & & & & & & \\
\hline \multirow[t]{2}{*}{ Her İki Akciğer Max } & SBRT & 11.00 & 77.00 & \multirow{2}{*}{70.53} & \multirow{2}{*}{7.13} & \multirow{2}{*}{61.45} & \multirow{2}{*}{78.62} & \multirow{2}{*}{0.00} & \multirow{2}{*}{$0.00^{*}$} \\
\hline & IMRT & 4.00 & 28.00 & & & & & & \\
\hline \multirow[t]{2}{*}{ Her İki Akciğer Ortalama } & SBRT & 6.36 & 44.50 & \multirow{2}{*}{3.96} & \multirow{2}{*}{1.12} & \multirow{2}{*}{1.78} & \multirow{2}{*}{5.35} & \multirow{2}{*}{16.50} & \multirow{2}{*}{0.31} \\
\hline & IMRT & 8.64 & 60.50 & & & & & & \\
\hline \multirow[t]{2}{*}{ Süre } & SBRT & 6.71 & 47.00 & \multirow{2}{*}{775.22} & \multirow{2}{*}{160.89} & \multirow{2}{*}{565.40} & \multirow{2}{*}{1129.40} & \multirow{2}{*}{19.00} & \multirow{2}{*}{0.48} \\
\hline & IMRT & 8.29 & 58.00 & & & & & & \\
\hline
\end{tabular}

Hacim.

3 cm'lik tümör ve 2.5 cmlik kesit alanı için Mann Whitney U testi sonucunda PTV max için SBRT ve IMRT teknikleri arasında SBRT lehine anlamlı farklılık saptanmıştır $(\mathrm{p}<0.05) .3 \mathrm{~cm}$ 'lik tümör ve 2.5 cmlik kesit alanı için her iki akciğer max için uygulanan SBRT ve IMRT teknikleri arasında SBRT lehine anlamlı farklılık saptanmıştır $(\mathrm{p}<0.05)$ (Tablo 2).

$5 \mathrm{~cm}$ 'lik tümör ve $5 \mathrm{~cm}$ 'lik kesit alanında Mann Whitney U testi sonucunda PTV max için SBRT ve IMRT teknikleri arasında SBRT lehine anlamlı farklılık saptanmıştır $(\mathrm{p}<0.05) .5 \mathrm{~cm}$ 'lik tümör ve $5 \mathrm{~cm}$ 'lik kesit alanı için her iki akciğer max için uygulanan SBRT ve IMRT teknikleri arasında SBRT lehine anlamlı farklılık saptanmıştır $(\mathrm{p}<0.05)$ (Tablo 3).

Çalışma Kosta dozu açısından değerlendirildiğinde 1 cm'lik tümör boyutunda kullanılan $1 \mathrm{~cm}$ 'lik jaw için $2.5 \mathrm{~cm}$ 'lik ve $5 \mathrm{~cm}$ 'lik sirasiyla Kosta $\max (\mathrm{p}=0.95$, $\mathrm{p}=0.95, \mathrm{p}=0.95)$ Kosta ortalama $(\mathrm{p}=1.0, \mathrm{p}=0.85, \mathrm{p}=0.75)$ ve Kosta V5 ( $\mathrm{p}=0.90, \mathrm{p}=0.75, \mathrm{p}=0.95)$ bulunmuştur ve yapılan istatistiksel analiz sonucunda anlamlı bir farklılık bulunamamıştır $(\mathrm{p}>0.05)$.
Çalışmamızda kalp için elde edilen bulgularda $1 \mathrm{~cm}$ 'lik tümör boyutunda kullanılan $1 \mathrm{~cm}$ 'lik jaw için $2.5 \mathrm{~cm}$ ' lik ve 5 cm'lik sirasıyla Kalp max $(\mathrm{p}=0.95, \mathrm{p}=0.41$, $\mathrm{p}=0.65)$ Kalp ortalama $(\mathrm{p}=0.90, \mathrm{p}=0.75, \mathrm{p}=0.95)$ ve Kalp V5 ( $\mathrm{p}=0.85, \mathrm{p}=0.75, \mathrm{p}=0.65)$ bulunmuştur ve yapılan istatistiksel analiz sonucunda anlamlı bir farklılık bulunamamıştır ( $\mathrm{p}>0.05)$.

Çalışmamızda özefagus için elde edilen bulgularda 1 cm'lik tümör boyutunda kullanılan $1 \mathrm{~cm}$ 'lik jaw için $2.5 \mathrm{~cm}$ 'lik ve 5 cm'lik sirasıyla özefagus $\max (\mathrm{p}=0.48$, $\mathrm{p}=0.75, \mathrm{p}=0.85)$ özefagus mean $(\mathrm{p}=0.65, \mathrm{p}=0.85, \mathrm{p}=0.96)$ ve özefagus V5 ( $\mathrm{p}=0.75, \mathrm{p}=0.85, \mathrm{p}=0.95)$ bulunmuştur ve yapılan istatistiksel analiz sonucunda anlamlı bir farklılık bulunamamıştır ( $\mathrm{p}>0.05)$.

Çalışmamızda medulla için elde edilen bulgularda $1 \mathrm{~cm}$ ' lik tümör boyutunda kullanılan $1 \mathrm{~cm}$ 'lik jaw için $2.5 \mathrm{~cm}$ ' lik ve $5 \mathrm{~cm}$ ' lik sirasiyla medulla $\max (\mathrm{p}=0.65, \mathrm{p}=0.65$, $\mathrm{p}=0.85)$ medulla ortalama $(\mathrm{p}=0.85, \mathrm{p}=0.57, \mathrm{p}=0.90)$ ve medulla V5 $(\mathrm{p}=1.00, \mathrm{p}=0.44, \mathrm{p}=1.00)$ bulunmuştur ve yapılan istatistiksel analiz sonucunda anlamlı bir farklılık bulunamamıştır ( $\mathrm{p}>0.05)$. 
Tablo 3: PTV max, PTV D95, her iki akciğer max, ortalama ve sürenin $5 \mathrm{~cm}$ 'lik tümör boyutunda $5 \mathrm{~cm}$ jaw kullanılarak elde edilen doz değerlerinin ortalama, standart sapmaları,minimum, maksimum ve p değerleri.

\begin{tabular}{lccccccccc|}
\hline & & $\begin{array}{c}\text { Mean- } \\
\text { Rank }\end{array}$ & $\begin{array}{c}\text { Sum of } \\
\text { Ranks }\end{array}$ & X & SS & Min & Max & M-U & p \\
\hline \multirow{2}{*}{ PTV max } & SBRT & 11.00 & 77.00 & 70.13 & 7.14 & 61.79 & 77.94 & 0.00 & $0.00^{*}$ \\
PTV & IMRT & 4.00 & 28.00 & & & & & & \\
D95 & SBRT & 5.29 & 37.00 & 58.57 & 2.13 & 53.05 & 60.82 & 9.00 & 0.05 \\
\multirow{4}{*}{ Her İki Akciğer Max } & IMRT & 9.71 & 68.00 & & & & & & \\
& SBRT & 11.00 & 77.00 & & & & & & \\
\multirow{3}{*}{ Her İki Akciğer Ortalama } & IMRT & 4.00 & 28.00 & 70.14 & 7.12 & 61.99 & 77.94 & 0.00 & $0.00^{*}$ \\
& SBRT & 5.43 & 38.00 & & & & & & \\
Süre & IMRT & 9.57 & 67.00 & 8.88 & 1.92 & 3.68 & 11.35 & 10.00 & 0.06 \\
SBRT: Stereotaktik Beden Radyoterapisi, IMRT: Yoğunluk Ayarli Radyoterapi, SS: Standart Sapma, M-U: Mann Whitney U, PTV: Planlanan Hedef
\end{tabular}

Hacim.

Çalışmamızda tedavi süreleri için elde edilen bulgularda $1 \mathrm{~cm}$ ' lik tümör boyutunda kullanılan $1 \mathrm{~cm}$ 'lik jaw için $2.5 \mathrm{~cm}$ 'lik ve $5 \mathrm{~cm}$ 'lik sirasıyla süre $(\mathrm{p}=0.048, \mathrm{p}=0.28$, $\mathrm{p}=0.95$ ) bulunmuştur ve yapılan istatistiksel analiz sonucunda $1 \mathrm{~cm}$ 'lik jaw için IMRT lehine anlamlı bir farklılık bulunmuştur $(p<0.05)$. Kullanılan 2.5 ve 5 cm'lik jaw alanlarında anlamlı bir farklılık bulunamamıştır $(\mathrm{p}>0.05)$.

3 cm'lik tümör boyutunda kullanılan $1 \mathrm{~cm}$ 'lik jaw için 2.5 cm'lik ve 5 cm'lik sırasıyla süre $(p=0.14, p=0.48, p=0.65)$ bulunmuştur ve yapılan istatistiksel analiz sonucunda anlamlı bir farklılık bulunamamıştır ( $\mathrm{p}>0.05) .5 \mathrm{~cm}$ 'lik tümör boyutunda kullanılan $1 \mathrm{~cm}$ 'lik jaw için $2.5 \mathrm{~cm}$ 'lik ve 5 cm'lik sırasıyla süre $(p=0.48, p=0.95, p=0.85)$ bulunmuştur ve yapılan istatistiksel analiz sonucunda anlamlı bir farklılık bulunamamıştır ( $\mathrm{p}>0.05)$.

Çalışmamızda $3 \mathrm{~cm}$ 'lik tümör boyutunda ve $5 \mathrm{~cm}$ 'lik tümör boyutunda yapılan istatistiksel analiz sonucunda kritik organlarda (her iki akciğer hariç) anlamlı bir farklılık olmadığı saptanmıştır.

\section{TARTIŞMA}

Radyoterapinin amacı hedef hacime mümkün olan maksimum dozun verilebilmesi ve kritik organların korunabilmesidir. Radyoterapinin uygulanmaya başlandığ1 ilk günden bu yana yeni teknikler geliştirilmektedir $(12,13)$. Radyoterapi tekniğinin gelişmiş yöntemi olan SBRT ve IMRT teknikleri, hedef üzerindeki keskin doz düşüşüyle sağlıklı dokuların çok iyi korunmasını sağlamaktadır. (14). SBRT tekniği 5 veya 5 'ten küçük fraksiyonlarda yüksek dozlar için kullanılmaktadır ve tedavi fraksiyon başına yüksek dozlar içerdiğinden birkaç fraksiyon halinde verilmektedir. IMRT tekniği ise yoğunluk farklılıkları oluşturulmuş farklı açılardan 1şınlama yaparken doz dağılımını ve hedef hacim dozunu daha iyi kontrol edebilmektedir $(15,16)$. Bu çalışmada akciğer kanseri tanısı almış 7 hasta seçilerek tomoterapi cihazında iki farklı teknik kullanılarak elde edilen doz dağılımlarının ve çevre dozların karşılaştırılması amaçlanmıştır. Bunun için her bir hastada tümör boyutları $1 \mathrm{~cm}, 3 \mathrm{~cm}$ ve $5 \mathrm{~cm}$ olacak şekilde BT planında çizilip tomoterapi planlama cihazına aktarılmıştır. Aynı zamanda tomoterapi cihazının kesit (jaw) alanı $1 \mathrm{~cm}, 2.5 \mathrm{~cm}$ ve 5 cm olarak her bir tümör boyutunda denenip bu vakalar için hem SBRT tekniği hem de IMRT tekniği kullanılarak planlamalar yapılmıştır. Tedavi planlamalarından doz hacim histogramları elde edilmiştir ve bu histogramlardan hedef ve kritik organların aldığ 1 dozlar ve bu dozları alan hacimleri belirlenmiştir. Çalışmanın asıl amacı; SBRT ve IMRT tekniklerinin karşılaştırılmasının sonucunda, tümöre verilen dozun hangi teknikle daha iyi sonuçlar verdiğini ve tümörün çevresinde bulunan kritik organların (kalp, kosta, medulla, özefagus, her iki akciğer) aldıkları dozlar; hangi teknikle, daha iyi sonuçlar verdiğini saptamaktır. Çalışmada akciğer kanserli 7 tane hasta verisi kullanılarak tümör boyutları ve jaw alanları değiştirilerek, her iki teknikte de tedavi planları oluşturulmuştur. $\mathrm{Bu}$ tedavi planlarında, PTV'ye tanımlanan dozun \%95'i sağlanırken, kritik organların da mümkün olduğunca korunması planlanmıştır. Planlamalarda; 6 MV x-1şın enerjisine sahip cihazın, SBRT ve IMRT tekniklerinde akciğere (PTV'ye) 60 Gy/3 fraksiyon olmak üzere toplam doz tanımlanarak sanal RT planları oluşturulmuştur. Çalışmada SBRT ve IMRT tüm planlamalarda, kesit genişliği sırasıyla $1 \mathrm{~cm}$, $2.5 \mathrm{~cm}$ ve $5 \mathrm{~cm}$ ve modülasyon faktörü 1.8 kullanılmıştır. Pitch faktörü ise SBRT'de 0.100 ve IMRT'de 0.287 'dir. Yapılan çalışmada $1 \mathrm{~cm}$ 'lik tümör boyutu için kullanılan 1 cm'lik, $2.5 \mathrm{~cm}$ 'lik ve $5 \mathrm{~cm}$ 'lik jaw alanlarında hedef hacim PTV max ve PTV D95 için elde edilen bulgularda SBRT tekniğinin daha iyi sonuçlar verdiği sonucuna ulaşılmıştır. $3 \mathrm{~cm}$ 'lik tümör boyutunda kullanılan $1 \mathrm{~cm}$ 'lik, $2.5 \mathrm{~cm}$ 'lik ve $5 \mathrm{~cm}$ 'lik jaw alanlarında hedef hacim PTV max için elde edilen bulgularda SBRT lehine anlamlı bir farklılık saptanmıştır $(\mathrm{p}<0.05) .5 \mathrm{~cm}$ 'lik tümör boyutunda ise kullanılan $1 \mathrm{~cm}$ 'lik, $2.5 \mathrm{~cm}$ 'lik ve $5 \mathrm{~cm}$ 'lik jaw alanlarında hedef hacim PTV max için elde edilen bulgularda SBRT lehine anlamlı bir farklılık saptanmıştır $(\mathrm{p}<0.05)$.

Andrea Holt ve arkadaşlarının yapmış oldukları çalışmada 27 akciğer kanserli olgunun tedavisinde SBRT tekniğinin IMRT tekniğine göre daha iyi sonuçlar verdiği gözlemlenmiştir. Gregory Videtic ve arkadaşlarının 


\section{Phnx Med J. November 2021, Volume 3 No 3}

yaptığı çalışmada 26 akciğer kanserli hastada uygulanan SBRT tekniğinin mükemmel lokal kontrol sağladığ gözlemlenmiştir (17). Ashleigh Weyh ve arkadaşlarının yapmış oldukları çalışmalarında SBRT tekniğinin IMRT tekniğine göre dozimetrik olarak daha iyi performans gösterdiği kanıtlanmıştır $(18,19)$. Yaptığımız çalışmada da bu yapılan çalışmalar gibi özellikle PTV max ve her iki akciğer dozlarında SBRT'nin daha olumlu etkilerinin olduğu soncuna varılmıştır. Yapılan çalışmada her iki teknikte kritik organları korumuştur fakat hedef hacim ve her iki akciğer açısından SBRT daha iyi sonuçlar vermiştir. Diğer kritik organ dozları açısından her iki teknikte benzer sonuçlar vermiştir.

Çıkar Çatışması: Yazar çıkar çatışması olmadığını beyan eder.

Etik: İstanbul Aydın Üniversitesi Girişimsel Olmayan Klinik Araştırmalar Etik Kurulu (23.12.2020 - 2020/317)

\section{KAYNAKLAR}

1. Haasbeek CJ, Slotman BJ, Senan S. Radiotherapy for lung cancer: clinical impact of recent technical advances. Lung Cancer. 2009;64(1):1-8.

2. Wang J, Olag J, Ultmann RE. 1999. Assessment of pulmonary complications after lung resection. Ann Thorac Surgery. 1999;67(5):1444-7. doi: 10.1016/s0003-4975(99)00255-6.

3. Khan FM. The Physics of Radiation Therapy. Lippincott Williams \& Wilkins, Philadelphia, USA; 2003.

4. Field JK. Selection and validation of new lung cancer markers for the molecular pathological assessment of individuals with a high risk of developing lung cancer. In: Brambilla C, Brambilla E. (Editors). Lung tumors fundamental biology and clinical management. New York: Marcel Dekker Inc; 1999. pp. 287-302.

5. Chang JY, Bradley JD, Govindan R, Komaki R. Lung. In: Perez CA, Brady LW, editors. Principles and Practice of Radiation Oncology. 5th ed. Philadelphia: Lippincott Williams \& Wilkins; 2008. pp. 1076-109.

6. Timmerman RD, Paulus R, Pass HI, Gore EM, Edelman MJ, Galvin J, et al. Stereotactic Body Radiation Therapy for Operable Early-Stage Lung Cancer: Findings From the NRG Oncology RTOG 0618 Trial. JAMA Oncol 2018;4(9):1263-1266. doi: 10.1001/jamaoncol.2018.1251.

7. Zheng M. Classification and Pathology of Lung Cancer. Surgical Oncology Clinics of North America. 2016;25(3):447-68. doi: 10.1016/j. soc.2016.02.003.

8. Flehinger BJ, Kimmel M, Melamed MR. The Effect of Surgical Treatment on Survival from Early Lung Cancer. Implications for screening. Chest. 1992;101(4):1013-8. doi: 10.1378/chest.101.4.10131

9. Webb S."Intensity-modulated radiation therapy Medical Science Series”, IOP. Publishing Ltd. Bristol, UK. 2001.

10. Peñagarícano JA, Yan Y, Corry P, Moros E, Ratanatharathorn V. Retrospective Evaluation of Pediatric Cranio-Spinal Axis Irradiation Plans with the Hi-ART Tomotherapy System. Technology in Cancer Research \& Treatment. 2007;6(4):355-60.doi: 10.1177/153303460700600413.

11. Erkan T, Melek NY, Cem O, Ali AY. Prevention of acute radiation-induced esophagitis with glutamine in non-small cell lung cancer patients treated with radiotherapy: evaluation of clinical and dosimetric parameters. Lung Cancer. 2009;63(3):393-9. doi: 10.1016/j.lungcan.2008.06.015.

12. Baumann M, Cordes N, Haase M, Zips D. Molekuler Cancer and Radiation Biology. Principles and Practice of Radiation Oncology (5th ed). Lippincott Williams \& Wilkins; 2008. pp. 109-121.

13. Galvin JM, Ezzell G, Eisbrauch A, Yu C, Butler B, Xiao Y, et al. Implementing IMRT in clinical practice: A joint document of the American Society for Therapeutic Radiology and Oncology and the American Association of Physicist in Medicine. Int. J. Radiat. Oncol. Biol. Phys. 2004;58(5):1616-1634.

14. Gillette EL, McChesney SL, Hoopes PJ.1985. Isoeffect curves for radiation-induce cardiomyopathy in the dog. Int J Radiat Oncol Biol Phys. 1985;11(12):2091-7. doi: 10.1016/0360-3016(85)90089-6.

15. Aras S, İkizceli T, Aktan M. Dosimetric Comparison of Three-Dimensional Conformal Radiotherapy (3D-CRT) and Intensity Modulated Radiotherapy Techniques (IMRT) with Radiotherapy Dose Simulations for Left-Sided Mastectomy Patients. Eur J Breast Health. 2019;15(2):8589.

16. Schultheiss TE, Higgins EM, El-Mahdi HM. The latent period in radiation myelopathy. Int J Radiat Oncol Biol Phys. 1984;10:1109-15

17. Gregory MMV, Kevin S, Chandana R, Stephen G, Matthew K, Edward C, Toufik D. Intensity- modulated radiotherapy-based stereotactic body radiotherapy for medically inoperable early-stage lung cancer: excellent local control. Int J Radiat Oncol Biol Phys. 2010;77(2):344-9. doi: 10.1016/j.ijrobp.2009.05.004

18. Ashleigh W, Andre K, Adria N, Jordan M,Danielle L. Lung SBRT: dosimetric and delivery comparison of Rapid Arc, TomoTherapy, and IMRT. Journal of Applied Clinical Medical Physics. 2013;14(4):4065. doi: 10.1120/jacmp.v14i4.4065

19. Kissick MW, Fenwick J, James JA, Jeraj R, Kapatoes JM, Keller H, et al. The helical tomotherapy thread effect. Medical Physics. 2005 May;32(5):1414-23. doi: 10.1118/1.1896453. 